University of Nebraska - Lincoln

DigitalCommons@University of Nebraska - Lincoln

Faculty Papers and Publications in Animal

Science

Animal Science Department

2019

\title{
Maternal age influences the number of primordial follicles in the ovaries of yearling Angus heifers
}

\author{
Sarah C. Tenley \\ University of Nebraska-Lincoln, sctenley09@gmail.com \\ Renata Spuri Gomes \\ University of Nebraska - Lincoln, rspurigomes2@unl.edu \\ Shelby L. Rosasco \\ New Mexico State University \\ Emmalee J. Northrop \\ South Dakota State University \\ Jerica J. J. Rich \\ South Dakota State University
}

See next page for additional authors

Follow this and additional works at: https://digitalcommons.unl.edu/animalscifacpub

Part of the Genetics and Genomics Commons, and the Meat Science Commons

Tenley, Sarah C.; Gomes, Renata Spuri; Rosasco, Shelby L.; Northrop, Emmalee J.; Rich, Jerica J. J.; McNeel, Anthony K.; Summers, Adam F.; Miles, Jeremy R.; Chase, Chadwick C. Jr.; Lents, Clay A.; Perry, George A.; Wood, Jennifer R.; Cupp, Andrea S.; and Cushman, Robert A., "Maternal age influences the number of primordial follicles in the ovaries of yearling Angus heifers" (2019). Faculty Papers and Publications in Animal Science. 1051.

https://digitalcommons.unl.edu/animalscifacpub/1051

This Article is brought to you for free and open access by the Animal Science Department at DigitalCommons@University of Nebraska - Lincoln. It has been accepted for inclusion in Faculty Papers and Publications in Animal Science by an authorized administrator of DigitalCommons@University of Nebraska Lincoln. 


\section{Authors}

Sarah C. Tenley, Renata Spuri Gomes, Shelby L. Rosasco, Emmalee J. Northrop, Jerica J. J. Rich, Anthony K. McNeel, Adam F. Summers, Jeremy R. Miles, Chadwick C. Chase Jr., Clay A. Lents, George A. Perry, Jennifer R. Wood, Andrea S. Cupp, and Robert A. Cushman 


\title{
Maternal age influences the number of primordial follicles in the ovaries of yearling Angus heifers
}

\author{
Sarah C. Tenley ${ }^{\mathrm{a}}$, Renata Spuri Gomes ${ }^{\mathrm{a}}$, Shelby L. Rosasco ${ }^{\mathrm{b}}$, Emmalee J. Northrop ${ }^{\mathrm{c}}$, \\ Jerica J.J. Rich ${ }^{\mathrm{c}}$, Anthony K. McNeel ${ }^{\mathrm{d}, 1}$, Adam F. Summers ${ }^{\mathrm{b}}$, Jeremy R. Miles ${ }^{\mathrm{d}}$, \\ Chadwick C. Chase Jr. ${ }^{\mathrm{d}}$, Clay A. Lents ${ }^{\mathrm{d}}$, George A. Perry ${ }^{\mathrm{c}}$, Jennifer R. Wood ${ }^{\mathrm{a}}$, \\ Andrea S. Cupp ${ }^{\text {a }}$, Robert A. Cushman ${ }^{\mathrm{d}, *, 2}$ \\ a Department of Animal Science, University of Nebraska-Lincoln, Lincoln, NE, USA \\ ${ }^{\mathrm{b}}$ Department of Animal and Range Sciences, New Mexico State University, Las Cruces, NM, USA \\ ${ }^{\mathrm{c}}$ Department of Animal Science, South Dakota State University, Brookings, SD, USA \\ ${ }^{\mathrm{d}}$ USDA, ARS, U.S. Meat Animal Research Center, Clay Center, NE, USA
}

\section{A R T I C L E I N F O}

\section{Keywords:}

Ovarian reserve

Puberty

Heifer

Fetal programming

\begin{abstract}
A B S T R A C T
The number of antral follicles detectable by ultrasonography in heifers is influenced by age of the dam, because daughters of primiparous cows have fewer antral follicles than daughters of mature cows. We, therefore, hypothesized that heifers with primiparous dams would have fewer primordial follicles in their ovaries than heifers born to mature $(4+y)$ cows. Angus heifers ( $n=464$ ) were submitted for ultrasonographic evaluation of antral follicle number at 325, 355, and $385 \mathrm{~d}$ of age. Ovaries were collected from a random subset of heifers $(n=79)$ and processed for histological evaluation to determine number of primordial follicles. A greater percentage of heifers with primiparous dams had a corpus luteum at first ultrasonographic examination; however, a greater percentage of heifers with multiparous dams had ovulated by the start of breeding $(P<0.01)$. Heifers with primiparous dams had fewer antral follicles detectable by ultrasonography $(P<0.01)$. Heifers with primparous dams had fewer surface antral follicles on their ovaries $(P<0.01)$, and the number of primordial follicles per histological section was less for heifers with primiparous dams $(P=0.02)$. These data indicate that the lesser number of antral follicles detectable by ultrasonography in heifers with primparous dams is due to less ovarian follicle reserves. Selecting replacement heifers from mature dams may result in daughters
\end{abstract}

\footnotetext{
* Corresponding author at: USDA, ARS, US Meat Animal Research Center, Nutrition and Environmental Management Research Unit, P.O. Box 166, Clay Center, NE 68933-0166, USA.

E-mail address: bob.cushman@ars.usda.gov (R.A. Cushman).

${ }^{1}$ Current address: Zoetis Inc., Kalamazoo, MI, USA.

${ }^{2}$ The U.S. Department of Agriculture (USDA) prohibits discrimination in all its programs and activities on the basis of race, color, national origin, age, disability, and where applicable, sex, marital status, familial status, parental status, religion, sexual orientation, genetic information, political beliefs, reprisal, or because all or part of an individual's income is derived from any public assistance program. (Not all prohibited bases apply to all programs.) Persons with disabilities who require alternative means for communication of program information (Braille, large print, audiotape, etc.) should contact USDA's TARGET Center at (202) 720-2600 (voice and TDD). To file a complaint of discrimination, write to USDA, Director, Office of Civil Rights, 1400 Independence Avenue, S.W., Washington, D.C. 20250-9410, or call (800) 795-3272 (voice) or (202) 720-6382 (TDD). USDA is an equal opportunity provider and employer.
} 
with greater fertility and reproductive longevity; however, further research is necessary to determine if interactions between size of the ovarian follicle reserve and age at puberty influence fertility and reproductive longevity in replacement heifers.

\section{Introduction}

In cattle, primordial follicles form at day 90 of gestation and gain the capacity to activate and enter the growing pool by day 150 of gestation (Fortune et al., 2013). From this time forward, the number of primordial follicles slowly decreases, and depletion of primordial follicles is a mechanism that contributes to reproductive senescence in mammalian females. Thus, the primordial follicles that form during fetal development represent the lifetime reproductive potential of a heifer (e.g., the ovarian reserve; reviewed in Fortune et al., 2013). Given the importance of the ovarian follicle reserve to reproductive longevity, very little is known about the mechanisms that control formation and depletion of primordial follicles, because it is challenging to monitor microscopic events that occur. One proxy that can be used to estimate the size of the ovarian reserve is ultrasonographic determination of antral follicle number (Cushman et al., 2009). The number of antral follicles detectable by ultrasonography is highly repeatable (Burns et al., 2005; McNeel et al., 2017; Morotti et al., 2018), and the number of antral follicles is positively correlated with the number of microscopic primordial follicles in cattle ovaries (Cushman et al., 1999; Ireland et al., 2008).

Walsh et al. (2014) reported that maternal age affected the number of antral follicles detectable by ultrasonography in the ovaries of the daughters at a year of age. In this previous study, Holstein heifers that were born to heifers had fewer antral follicles detectable by ultrasonography at a year of age than Holstein heifers that were born to multiparous cows. Similarly, Angus heifers with diminished numbers of antral follicles detectable by ultrasonography (14.5 \pm 0.8 follicles) had dams that were younger than the dams of Angus heifers with increased numbers of antral follicles (31.1 \pm 0.8 follicles, McNeel et al., 2017). More recently, it was reported that heifer born to mature beef cows had greater circulating concentrations of anti-Müllerian hormone (AMH), a blood marker of size of the ovarian reserve, and greater fertility than heifers with primiparous dams (Akbarinejad et al., 2018). While both number of antral follicles (Cushman et al., 1999) and circulating concentrations of AMH (Ireland et al., 2008) are generally correlated to the size of the ovarian reserve, there are studies where differences in numbers of primordial follicle do not result in differences in numbers of antral follicles (Freetly et al., 2014; Amundson et al., 2015). It, therefore, is important to perform the histological evaluation to clearly identify whether there are differences in the size of the ovarian follicle reserve between heifers with primiparous dams as compared with those from multiparous dams as a first step in understanding the mechanisms behind these differences. In the present study, we tested the hypothesis that yearling heifers with primiparous Angus dams would have fewer primordial follicles in their ovaries than yearling Angus heifers with multiparous dams.

\section{Materials and methods}

\subsection{Heifers}

All procedures were approved by the U.S. Meat Animal Research Center (USMARC) Animal Care and Use Committees in accordance with the FASS guidelines for the care and use of agricultural animals in research. Commercial Angus heifers $(n=116 /$ year; total 464) were evaluated for antral follicle count at an average of 325, 355, and $385 \mathrm{~d}$ of age as described previously (McNeel et al., 2017). Briefly, heifers that were born between March and May in 2012-2015 were weaned and moved to the USMARC feedlot in the fall. Heifers were fed the standard USMARC heifer development diet to attain 55\% of predicted mature body weight by 14 months of age. When the cohort of heifers reached an average of $325 \pm 3 \mathrm{~d}$ of age, $355 \pm 3 \mathrm{~d}$ of age, and $385 \pm 3 \mathrm{~d}$ of age, they were weighed and transrectal ultrasonographic examination of the ovaries was performed by a single technician using an Aloka-500 ultrasonic machine and a 7.5 MHz linear array transducer (Aloka, Wallingford, CT) to determine antral follicle count and corpus luteum (CL) number (McNeel and Cushman, 2015; McNeel et al., 2017). Following the third ultrasonography, heifers that were not slaughtered in the USMARC abattoir to collect ovaries for histological evaluation were placed with bulls that had passed a breeding soundness exam, and allowed to mate by natural service for $30 \mathrm{~d}$.

Two weeks following the second ultrasonographic examination at approximately a year of age, 79 heifers $(n=19-20$ heifers/ year) with dams representing three different age groups (Table 1) were slaughtered in the USMARC abattoir and ovaries were

Table 1

Number of heifers representing each age of dam class for ultrasonographic and morphometric analysis of follicle numbers.

\begin{tabular}{lll}
\hline & \multicolumn{2}{l}{ Method to Determine Follicle Number } \\
\cline { 2 - 3 } Age of Dam, y & Ultrasonography & Morphometry \\
\hline 2 & 84 & 14 \\
3 & 89 & 15 \\
$4+$ & 291 & 50 \\
\hline
\end{tabular}


collected for histological evaluation to determine the number of primordial, primary, and secondary follicles. The ovaries were removed from the reproductive tracts and all surface antral follicles $(\geq 1 \mathrm{~mm})$ were counted. The height and length of the ovaries were measured, taking care to only measure the ovary proper and avoid the CL, and the ovaries were weighed. The investigator performing the ovarian morphological measurements was uninformed as to the age of the dam of the heifer from which the ovaries originated. A representative cross-sectional piece of tissue ( $\sim 5 \mathrm{~mm}$ thickness) was cut from the center, perpendicular to the length of the ovary contra-lateral to the CL and fixed overnight in 10\% Neutral Buffered Formalin for histological evaluation (Cushman et al., 2001; Amundson et al., 2015). The ovarian tissues were rinsed in phosphate buffered saline for $1 \mathrm{~h}$ at room temperature, followed by $20 \%$ ethanol, $35 \%$ ethanol, $50 \%$ ethanol, and $70 \%$ ethanol, each for $1 \mathrm{~h}$ at room temperature to dehydrate the tissues. The ovarian tissue was subsequently embedded in paraffin. Five sections ( $6 \mu \mathrm{m}$ thickness) were collected and stained with hematoxylin and eosin. A minimum of ten sections was discarded between each section that was collected to ensure that the same follicles were not counted twice in consecutive sections. Follicles were only counted when the nucleus of the oocyte appeared in the section, further ensuring the prevention of double counting for secondary follicles.

\subsection{Histological evaluation of pre-antral follicle numbers}

Pre-antral follicles were classified as primordial, primary, or secondary as described previously (Cushman et al., 2001, 2002; Amundson et al., 2015). Briefly, a primordial follicle was defined as an oocyte surrounded by a single layer of squamous pregranulosa cells. A primary follicle was considered to be an oocyte surrounded by 1 or more cuboidal granulosa cells. A secondary follicle was defined as an oocyte surrounded by two or more layers of cuboidal granulosa cells. The number of follicles per section within each follicle class was totaled to ascertain a count per section for each follicle class. Because heifer was the experimental unit, the average number of follicles per section for each follicle class was calculated for each heifer. The average area of the sections was $326.7 \pm 1.9 \mathrm{~mm}^{2}$. The investigator performing the histological evaluations was uninformed as to the age of the dam of the heifer from which the ovarian sections originated.

\subsection{Statistical analyses}

Age of dam was grouped into three classifications (Table 1): 2-year-old dams (2), 3-year-old dams (3), and dams that were 4years-old or greater $(4+)$. The number of animals within each group for ultrasonographic evaluation and for morphological evaluation are presented in Table 1. For performance data, numbers of antral follicles detectable by ultrasonography and body weights were analyzed using the MIXED procedure of SAS. The model included the fixed effects of year, age of heifer (325, 355, or 385 d), age of dam $(2,3$, or $4+y)$, and the interaction of age of heifer and age of dam. Dam was a random effect to account for the same dam potentially having daughters represented in multiple years of the study. Percentage of heifers having a CL was analyzed using the GLIMMIX procedure of SAS with a model that included the fixed effects of year, age of heifer, age of dam, and the interaction of age of heifer and age of dam. Dam was included as a random effect. Percentage data were analyzed with a binomial distribution and a logit link. For morphological and histological data, ovarian measurements, surface antral follicle counts, and numbers of pre-antral follicles per section or per $\mathrm{mm}^{2}$ of tissue were analyzed using the MIXED procedure of SAS with a model that included the fixed effect of age of dam. Data are presented as the mean \pm the S. E. M.

To examine the relationship between pre-antral follicle numbers and surface antral follicle counts, Pearson correlations were calculated using the CORR procedure of SAS. As previously described, the average number of primordial, primary, and secondary follicle per histological section was calculated for each heifer before calculating the correlation to the surface antral follicle number. This approach was taken so that the heifer and not histological section was the experimental unit.

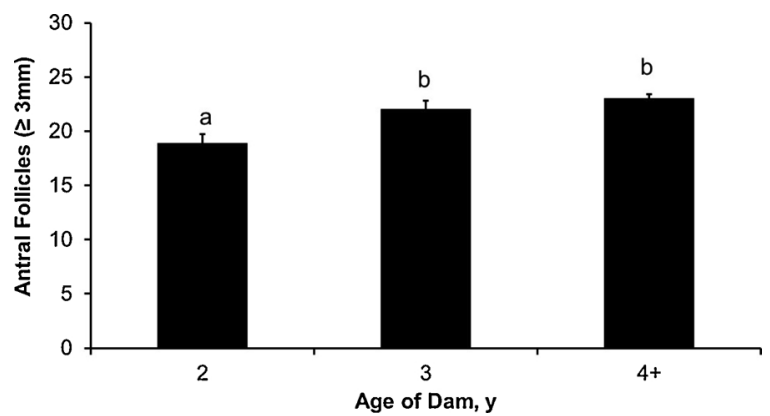

Fig. 1. Influence of age of dam on heifer ultrasonographic antral follicle count. Bars with different superscripts are different $(P<0.05)$. Age of dam influenced the number of antral follicles detectable by ultrasonography $(P<0.0001)$, because heifers born to heifers had fewer antral follicles than heifers born to 3-year-old cows or heifers born to mature $(4+\mathrm{y})$ dams. Data are presented as the mean \pm the S.E.M. 


\section{Results}

\subsection{Ultrasonographic measurements}

Based on within animal variance divided by between animal variance (Morotti et al., 2018), the repeatability of antral follicle counts within heifers was $80 \%$ in the present study. There was no interaction of age of heifer and age of dam on ultrasonographic antral follicle count $(P=0.56)$. Age of heifer also did not influence the number of antral follicles detectable by ultrasonography $(P=0.12)$; however, age of dam influenced the number of antral follicles detectable by ultrasonography $(P<0.0001)$. Across all three ultrasonographic examinations, heifers with primiparous dams had fewer antral follicles detectable by ultrasonography than heifers with 3- or 4+ year-old dams (Fig. 1).

There was an effect of the interaction of age of heifer and age of dam on percentage of heifers identified with a CL $(P=0.004$; Fig. 2). A greater percentage of heifers with primiparous dams had a CL at the first ultrasonographic examination compared to heifers with a 3- or 4+ year-old dam; however, a lesser cumulative percentage of heifers heifers with primiparous dams had a CL by the start of the breeding season compared to heifers with 3- or $4+$ year-old dams. The main effect of age of heifer had a significant influence on the cumulative percentage of heifers identified with a CL $(P<0.0001)$, because, as would be expected, the cumulative percentage of heifers identified with a CL increased as age of heifer increased.

\subsection{Ovarian morphometry}

The number of antral follicles $(\geq 1 \mathrm{~mm})$ on the surface of the ovaries was influenced by age of dam, such that heifers with primiparous dams had fewer follicles than heifers with $4+$ year-old dams $(P<0.01$; Fig. 3). Heifers with 3 -year-old dams had an intermediate number of surface antral follicles. Total ovarian weight, defined as the sum of the weights of the two ovaries within a heifer, was influenced by age of dam with heifers with $4+$ year-old dams having heavier ovaries than heifers with primiparous or 3year-old dams $(P=0.05$; Table 2$)$. Ovarian length, defined as the average length of the two ovaries within a heifer, tended to be greater in heifers with $4+$ year-old dams, compared to heifers with primiparous or 3-year-old dams $(P=0.08)$. Ovarian height was greater in heifers with mature $(4+y)$ dams than heifers with primparous or 3-year-old dams $(P=0.03)$.

The coefficient of variation for primordial follicle count across the five sections within a heifer was $11.5 \pm 1.1 \%$. Histological analysis of the ovaries revealed that the number of primordial follicles per section was greater in heifers with $4+$ year-old dams than heifers with 3-year-old dams $(P=0.02$; Fig. $4 \mathrm{~A})$. There was a strong tendency $(P=0.06)$ for the number of primary follicles per section to be greater in heifers with $4+$ year-old dams than heifers with primiparous dams (Fig. 4B). The number of secondary follicles per section was greater $(P=0.02)$ in heifers with $4+$ year-old dams than heifers with primiparous or 3 -year-old dams (Fig. 4C). Overall, there were positive correlations between the average number of pre-antral follicles per section and the number of surface antral follicles $(P<0.01$; Table 3$)$, supporting the hypothesis that differences in antral follicle numbers due to the age of the dam reflected differences in the size of the ovarian follicle reserve.

Because ovarian size was influenced by age of dam, the number of preantral follicles per $\mathrm{mm}^{2}$ of tissue (determined by calculating the area of an ellipse from the length and height of the histological section) was analyzed to determine if tissue density of follicles differed due to age of dam (Table 4). When corrected for the area of the sections, heifers with $4+$ year-old dams still had a greater number of primordial follicles per $\mathrm{mm}^{2}$ of ovary $(P=0.04)$. There was no influence of age of dam on the tissue density of primary follicles $(P=0.20)$; however, the tissue density of secondary follicles tended to be greater in heifers with $4+$ year-old dams than heifers with primiparous dams $(P=0.06)$.

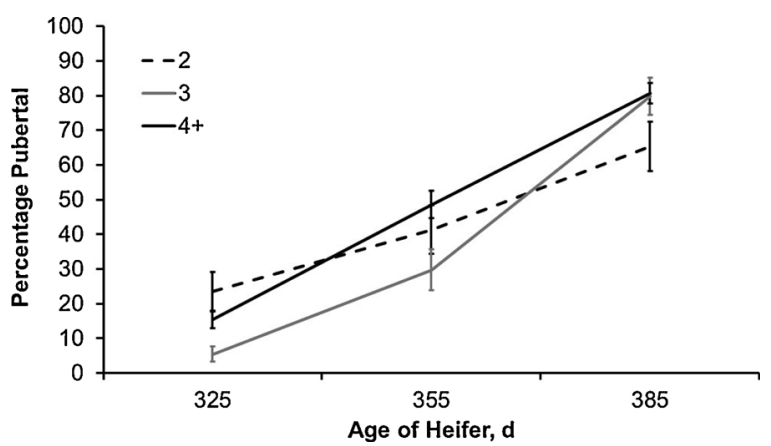

Fig. 2. Cumulative percentage of Angus heifers defined as pubertal due to being diagnosed with a CL detectable by ultrasonography. Age of heifer $(P<0.0001)$ affected the cumulative percentage of heifers that were pubertal, because the cumulative percentage of heifers with a CL increased with increasing age. There was also a significant interaction of age of heifer and age of dam $(P=0.004)$, because a greater percentage of heifers born to heifers were identified with a CL at the first examination, but a lesser cumulative percentage of heifers born to heifers had a CL at the final examination. Data are presented as the mean \pm the S.E.M. 


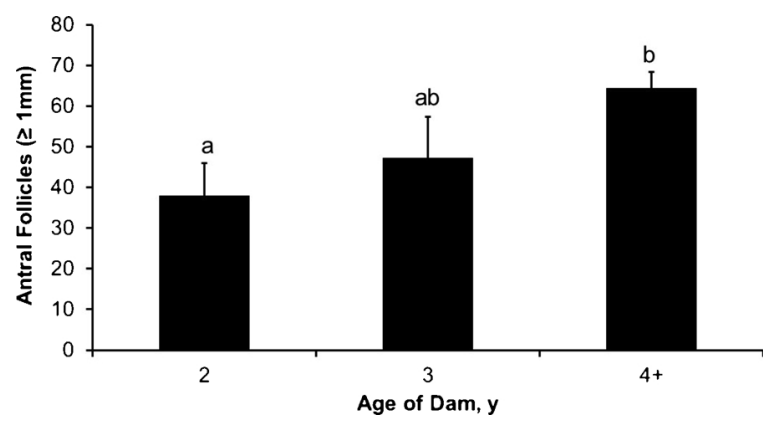

Fig. 3. Number of surface antral follicles $(\geq 1 \mathrm{~mm})$ in the combined ovaries counted at recovery after slaughter. Bars with different superscripts are different $(P<0.05)$. Heifers born to 2-year-old dams had fewer surface follicles than heifers born to mature $(4+\mathrm{y})$ dams $(P<0.01)$, while heifers born to 3-year-old dams were intermediate. Data are presented as the mean \pm the S.E.M.

Table 2

Effect of age of dam on ovarian morphology (mean \pm S. E. M.).

\begin{tabular}{|c|c|c|c|c|}
\hline \multirow[b]{2}{*}{ Phenotype } & \multicolumn{3}{|l|}{ Age of Dam, y } & \multirow[t]{2}{*}{$P$-value } \\
\hline & 2 & 3 & $4+$ & \\
\hline Total ovarian weight, $\mathrm{g}$ & $11.5 \pm 1.0^{\mathrm{a}}$ & $10.2 \pm 1.0^{\mathrm{a}}$ & $12.9 \pm 0.5^{\mathrm{b}}$ & 0.05 \\
\hline Ovarian length, mm & $27.8 \pm 1.1$ & $26.8 \pm 1.1$ & $29.4 \pm 0.6$ & 0.08 \\
\hline Ovarian height, $\mathrm{mm}$ & $15.1 \pm 0.7^{\mathrm{a}}$ & $15.9 \pm 0.7^{\mathrm{a}}$ & $17.3 \pm 0.4^{\mathrm{b}}$ & 0.03 \\
\hline
\end{tabular}

${ }^{\mathrm{ab}}$ Within a row, means with different superscripts are different.

\subsection{Body weights}

Heifers with $4+$ year-old dams were heavier at birth than heifers with primiparous dams or heifers with 3-year-old dams $(P<$ 0.0001; Table 5). Weight at weaning was also influenced by age of dam $(P=0.003)$. In this case, heifers with 3 -year-old dams weighed less at weaning than heifers with $4+$ year-old dams.

During the evaluation period, age of heifer and age of dam affected body weight $(P<0.0001$; Fig. 5); however, there was no interaction of age of heifer and age of dam $(P=0.42)$. As would be expected, heifers increased in body weight as they progressed from 325 to 385 d of age. Heifers with primiparous dams weighed less than heifers with 3 or $4+$ year-old dams.

\section{Discussion}

The results of the present study support the hypothesis that primordial follicle numbers are less in the ovaries of yearling Angus heifers with primparous dams compared to yearling Angus heifers with $4+$ year-old dams. While fewer antral follicles detectable by ultrasonography in the ovaries of heifers with primparous dams has been previously reported (Walsh et al., 2014), the findings in the present study are the first to indicate the number of microscopic follicles is also less. The developmental mechanisms that lead to this lesser number of primordial follicles are unknown but can be assumed to have occurred by 11 months of age, because even at the first ultrasonographic examination, heifers with primparous dams had fewer antral follicles than heifers with $4+$ year-old dams. The most likely mechanisms are either 1) decreased proliferation of primordial germ cells in utero leading to fewer primordial follicles being formed, or 2) accelerated depletion of the primordial follicles in the ovaries of the heifers with primparous dams leading to fewer primordial follicles at a year of age. There is certainly evidence for either of these, because both the maternal environment during gestation (Evans et al., 2012; Mossa et al., 2013; Akbarinejad et al., 2017) and nutritional status during the first year of life (Freetly et al., 2014; Amundson et al., 2015) influence the size of the ovarian follicle reserve in heifers. Further studies evaluating fetal ovaries and ovaries collected between birth and a year of age will be necessary to determine the exact timing of the divergence in primordial follicle numbers.

The fact that the number of primordial follicles is correlated to surface antral follicle counts and ultrasonographic antral follicle counts supports the relatively greater repeatability of antral follicle count in the present study and previous studies (Burns et al., 2005; McNeel et al., 2017; Morotti et al., 2018). There is no evidence of day of the estrous cycle or fluctuations in antral follicle numbers due to stage of the follicular wave influencing the number of pre-antral follicles in cattle (Rajakoski, 1960; Erickson, 1966). Because the number of primordial follicles correlated with the number of antral follicles, it seems very likely that the number of antral follicles detected by ultrasonography is a product of the size of the ovarian reserve. Antral follicle count should, therefore, be repeatable within a heifer, at least until her ovarian reserve begins to deplete with age. The fact that microscopic follicle populations recapitulate the ultrasonographic observations of differences in antral follicle count due to age of the dam (Walsh et al., 2014; McNeel et al., 2017) strongly supports this conclusion.

As would be expected, birth weights were less in heifers with primiparous dams. This is most likely a result of intra-uterine growth 

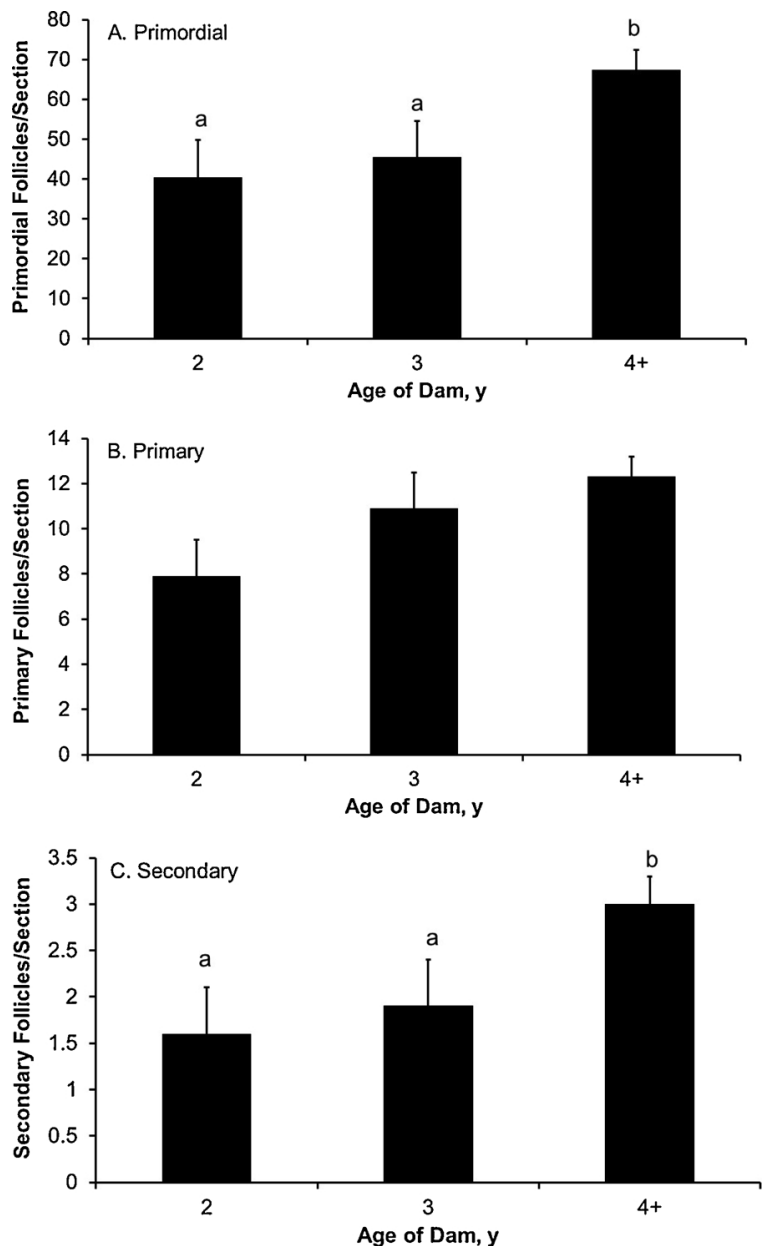

Fig. 4. Number of A) primordial follicles, B) primary follicles, or C) secondary follicles per histological section. Within a pre - antral follicle class, bars with different superscripts are different $(P<0.05)$. The number of primordial follicles per histological section $(P=0.02)$ and the number of secondary follicles per histological section were greater in heifers born to mature $(4+\mathrm{y})$ dams than to heifers born to 2-year-old dams. There was a tendency $(P=0.06)$ for heifers born to mature $(4+y)$ dams to have more primary follicles per histological section than heifers born to 2-year-old dams. Data are presented as the mean \pm the S.E.M.

Table 3

Pearson correlations between histological counts and surface antral follicle counts.

\begin{tabular}{llcc}
\hline Stage & Primary Follicles & Secondary Follicles & Antral Follicles \\
\hline Primordial Follicles & 0.67 & 0.47 & 0.45 \\
& $<0.0001$ & $<0.0001$ & $<0.0001$ \\
Primary Follicles & & 0.61 & 0.35 \\
Secondary Follicles & & $<0.0001$ & 0.002 \\
& & & 0.34 \\
& & & 0.002 \\
\hline
\end{tabular}

restriction on the fetuses of heifers, but whether it is a result of decreased nutrient transport or a result of intra-uterine crowding due to a smaller uterus in heifers is unclear. In a large study that did not examine influences of age of dam, Cushman et al. (2009) reported that 14-month-old heifers with lesser numbers of antral follicles detectable by ultrasonography weighed less at birth. This may be because a greater percentage of them were heifers with primiparous dams. The heifers with lesser numbers of follicles detectable by ultrasonography had a lesser pregnancy rate compared to heifers with greater numbers of antral follicles. The data from these two studies could indicate that the divergence in primordial follicle number is occurring during fetal development due to intra-uterine growth restriction in heifers with primiparous dams. Taken together, these data indicate that it is more desirable to select replacement heifers with dams that are $4+$ years of age.

A greater percentage of heifers from primiparous dams were identified with a CL at the first ultrasonographic examination. The 
Table 4

Effect of age of dam on numbers of preantral follicles per $\mathrm{mm}^{2}$ of ovarian tissue (mean \pm S.E.M.).

\begin{tabular}{lllll}
\hline & Age of Dam, $y$ & & \\
\cline { 2 - 4 } Phenotype & 2 & 3 & $4+$ & $0.18 \pm 0.01^{\mathrm{b}}$ \\
\hline Primordial Follicles $/ \mathrm{mm}^{2}$ & $0.11 \pm 0.02^{\mathrm{a}}$ & $0.13 \pm 0.03^{\mathrm{ab}}$ & $0.03 \pm 0.01$ & 0.04 \\
Primary Follicles $/ \mathrm{mm}^{2}$ & $0.02 \pm 0.01$ & $0.03 \pm 0.01$ & $0.009 \pm 0.001$ \\
Secondary Follicles $/ \mathrm{mm}^{2}$ & $0.004 \pm 0.002$ & $0.006 \pm 0.002$ & 0.06 \\
\hline
\end{tabular}

${ }^{\mathrm{ab}}$ Within a row, means with different superscripts are different.

Table 5

Effect of age of dam on birth weight, weaning weight, and age of heifer at first palpation (mean \pm S.E.M.).

\begin{tabular}{lllll}
\hline & Age of Dam, $y$ & & \\
\cline { 2 - 4 } Phenotype & 2 & 3 & $3+$ & $36.5 \pm 0.3^{\mathrm{c}}$ \\
\hline Birth Weight, $\mathrm{kg}$ & $29.6 \pm 0.5^{\mathrm{a}}$ & $35.2 \pm 0.5^{\mathrm{b}}$ & $183.3 \pm 1.2^{\mathrm{a}}$ & $<0.0001$ \\
Weaning Weight, kg & $180.4 \pm 2.2^{\mathrm{a}}$ & $170.5 \pm 2.1^{\mathrm{b}}$ & $317.5 \pm 0.8^{\mathrm{b}}$ & 0.003 \\
Age at First Palpation, d & $348.6 \pm 1.4^{\mathrm{a}}$ & $314.9 \pm 1.4^{\mathrm{b}}$ & $<0.0001$ \\
\hline
\end{tabular}

${ }^{\mathrm{abc}}$ Within a row, means with different superscripts are different.

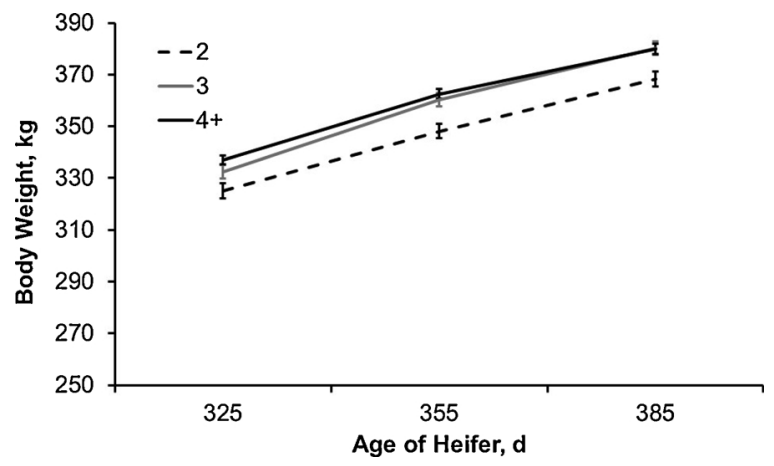

Fig. 5. Heifer body weights during the evaluation period (325-385 d of age). There was no interaction of age of heifer and age of dam $(P>0.05)$; however, both age of heifer and age of dam influenced body weights during the evaluation period $(P<0.0001)$. Data are presented as the mean \pm the S.E.M.

standard management practice for the USMARC herd is to breed heifers a month earlier than cows, and this practice resulted in the heifers with primiparous dams being older at the first ultrasonographic examination. It, therefore, is likely that a greater percentage of these heifers had a CL at the first examination because they were older than the heifers with 3- or 4+ year-old dams. Interestingly, by the final ultrasonographic examination just before the start of the breeding season, a greater cumulative percentage of heifers with 3 or $4+$ year-old dams had a CL. This is most likely due to the greater body weights of these heifers. The question becomes whether it would be a preferred practice to select heifers with primiparous dams that are more likely to have multiple estrous cycles before the start of the breeding season, because this has been associated with greater fertility (Byerley et al., 1987), or whether it would be more desirable to select heifers with $4+$ year-old dams that are more likely to be pubertal by the start of the breeding season, and to have a larger ovarian reserve. The interaction between the size of the ovarian follicle reserve and age at puberty remains questionable, because it has been reported to be beneficial in some cases (El-Sheikh Ali et al., 2017; Santa Cruz et al., 2018), and antagonistic in other cases (Snelling et al., 2012). Further analysis of data sets that incorporate heifer follicle counts and age at puberty with age of dam and lifetime productivity are required to accurately determine what effect the interaction of antral follicle count and age of dam has on lifetime reproductive capacity of replacement heifers.

In conclusion, the present results indicate that there may be reasons to select replacement heifers from mature $(4+\mathrm{y})$ cows. Although heifers with primiparous dams were older, a greater percentage of the heifers with $4+$ year-old dams were pubertal at the start of the first breeding season. In addition, these heifers had a greater density of primordial follicles per mm ${ }^{2}$ of ovarian tissue. The dams of heifers from the mature cows had already expressed the economically important trait of remaining in the herd to produce enough calves so that there was recovery of the development costs. Assuming a genetic component to reproductive longevity, these daughters of mature $(4+y)$ dams may have an advantage, and this advantage may be associated partially with a greater ovarian follicle reserve. It will be interesting to determine when during gametogenesis or folliculogenesis the divergence in primordial follicle number occurs, and if these lesser numbers of primordial follicles negatively affect the reproductive longevity of beef heifers with primiparous dams. 


\section{Conflict of interest statement}

The authors have no conflicts of interest to report.

\section{Acknowledgements}

The authors thank Chad Engle, Nels Johnson, Dave Kohmetscher, and USMARC Cattle Operations for expert care and handling of the animals; Sarah Knox and Darrell Light for management of the database; Elane Wright-Johnson for assistance with collection of ultrasonographic data; David Sypherd and Elane Wright-Johnson for technical assistance in the laboratory; and Donna Griess for assistance with manuscript preparation. This research was funded in part by ARS Project number 3040-31000-096-00D to RAC and CCC, and USMARC/UNL Collaboration Competitive grant 2014-2016 to ASC, RAC, and JRW to fund the graduate stipend for ST.

\section{References}

Akbarinejad, V., Gharagozlou, F., Vojgani, M., 2017. Temporal effect of maternal heat stress during gestation on the fertility and anti-Müllerian hormone concentration of offspring in bovine. Theriogenology 99, 69-78.

Akbarinejad, V., Gharagozlou, F., Vojgani, M., Bagheri Amirabadi, M.M., 2018. Nulliparous and primiparous cows produce less fertile female offspring with lesser concentration of anti-Müllerian hormone (AMH) as compared with multiparous cows. Anim. Reprod. Sci. 197, 222-230.

Amundson, O.L., Fountain, T.H., Larimore, E.L., Richardson, B.N., McNeel, A.K., Wright, E.C., Keisler, D.H., Cushman, R.A., Perry, G.A., Freetly, H.C., 2015. Postweaning nutritional programming of ovarian development in beef heifers. J. Anim. Sci. 93, 5232-5239.

Burns, D.S., Jimenez-Krassel, F., Ireland, J.L., Knight, P.G., Ireland, J.J., 2005. Numbers of antral follicles during follicular waves in cattle: evidence for high variation among animals, very high repeatability in individuals, and an inverse association with serum follicle-stimulating hormone concentrations. Biol. Reprod. 73, 54-62.

Byerley, D.J., Staigmiller, R.B., Berardinelli, J.G., Short, R.E., 1987. Pregnancy rates of beef heifers bred either on puberal or third estrus. J. Anim. Sci. 65, 645-650.

Cushman, R.A., DeSouza, J.C., Hedgpeth, V.S., Britt, J.H., 1999. Superovulatory response of one ovary is related to the micro- and macroscopic population of follicles in the contralateral ovary of the cow. Biol. Reprod. 60, 349-354.

Cushman, R.A., DeSouza, J.C., Hedgpeth, V.S., Britt, J.H., 2001. Alteration of activation, growth, and atresia of bovine preantral follicles by long-term treatment of cows with estradiol and recombinant bovine somatotropin. Biol. Reprod. 65, 581-586.

Cushman, R.A., Wahl, C.M., Fortune, J.E., 2002. Bovine ovarian cortical pieces grafted to chick embryonic membranes: a model for studies on the activation of primordial follicles. Hum. Reprod. 17, 48-54.

Cushman, R.A., Allan, M.F., Kuehn, L.A., Snelling, W.M., Cupp, A.S., Freetly, H.C., 2009. Evaluation of antral follicle count and ovarian morphology in crossbred beef cows: investigation of influence of stage of the estrous cycle, age, and birth weight. J. Anim. Sci. 87, 1971-1980.

El-Sheikh Ali, H., Kitahara, G., Takahashi, T., Mido, S., Sadawy, M., Kobayashi, I., Hemmi, K., Osawa, T., 2017. Plasma anti-Mullerian hormone profile in heifers from birth through puberty and relationship with puberty onset. Biol. Reprod. 97, 153-161.

Erickson, B.H., 1966. Development and senescence of the postnatal bovine ovary. J. Anim. Sci. 25, 800-805.

Evans, A.C., Mossa, F., Walsh, S.W., Scheetz, D., Jimenez-Krassel, F., Ireland, J.L., Smith, G.W., Ireland, J.J., 2012. Effects of maternal environment during gestation on ovarian folliculogenesis and consequences for fertility in bovine offspring. Reprod. Domest. Anim. 47 (Suppl (4)), 31-37.

Fortune, J.E., Yang, M.Y., Allen, J.J., Herrick, S.L., 2013. Triennial reproduction symposium: the ovarian follicular reserve in cattle: what regulates its formation and size? J. Anim. Sci. 91, 3041-3050.

Freetly, H.C., Vonnahme, K.A., McNeel, A.K., Camacho, L.E., Amundson, O.L., Forbes, E.D., Lents, C.A., Cushman, R.A., 2014. The consequence of level of nutrition on heifer ovarian and mammary development. J. Anim. Sci. 92, 5437-5443.

Ireland, J.L., Scheetz, D., Jimenez-Krassel, F., Themmen, A.P., Ward, F., Lonergan, P., Smith, G.W., Perez, G.I., Evans, A.C., Ireland, J.J., 2008. Antral follicle count reliably predicts number of morphologically healthy oocytes and follicles in ovaries of young adult cattle. Biol. Reprod. 79, $1219-1225$.

McNeel, A.K., Cushman, R.A., 2015. Influence of puberty and antral follicle count on calving day in crossbred beef heifers. Theriogenology $84,1061-1066$.

McNeel, A.K., Soares, E.M., Patterson, A.L., Vallet, J.L., Wright, E.C., Larimore, E.L., Amundson, O.L., Miles, J.R., Chase Jr., C.C., Lents, C.A., Wood, J.R., Cupp, A.S., Perry, G.A., Cushman, R.A., 2017. Beef heifers with diminished numbers of antral follicles have decreased uterine protein concentrations. Anim. Reprod. Sci. $179,1-9$.

Morotti, F., Moretti, R., Dos Santos, G.M.G., Silva-Santos, K.C., Ramos Cerqueira, P.H., Seneda, M.M., 2018. Ovarian follicular dynamics and conception rate in Bos indicus cows with different antral follicle counts subjected to timed artificial insemination. Anim. Reprod. Sci. 188, $170-177$.

Mossa, F., Carter, F., Walsh, S.W., Kenny, D.A., Smith, G.W., Ireland, J.L., Hildebrandt, T.B., Lonergan, P., Ireland, J.J., Evans, A.C., 2013. Maternal undernutrition in cows impairs ovarian and cardiovascular systems in their offspring. Biol. Reprod. 88, 92.

Rajakoski, E., 1960. The ovarian follicular system in sexually mature heifers with special reference to seasonal, cyclical, and left-right variations. Acta Endocrinol. Suppl. (Copenh) 34 (Suppl 52), 1-68.

Santa Cruz, R., Cushman, R.A., Vinoles, C., 2018. Antral follicular count is a tool that may allow the selection of more precocious Bradford heifers at weaning. Theriogenology 119, 35-42.

Snelling, W.M., Cushman, R.A., Fortes, M.R., Reverter, A., Bennett, G.L., Keele, J.W., Kuehn, L.A., McDaneld, T.G., Thallman, R.M., Thomas, M.G., 2012. Physiology and endocrinology symposium: how single nucleotide polymorphism chips will advance our knowledge of factors controlling puberty and aid in selecting replacement beef females. J. Anim. Sci. 90, 1152-1165.

Walsh, S.W., Mossa, F., Butler, S.T., Berry, D.P., Scheetz, D., Jimenez-Krassel, F., Tempelman, R.J., Carter, F., Lonergan, P., Evans, A.C., Ireland, J.J., 2014. Heritability and impact of environmental effects during pregnancy on antral follicle count in cattle. J. Dairy Sci. 97, 4503-4511. 